\title{
Combined spinal-epidural anesthesia for urgent cesarean section in a parturient with a single ventricle -a case report-
}

\author{
Stefano Catarci, Fabio Sbaraglia, Bruno Antonio Zanfini, Salvatore Vagnoni, \\ Luciano Frassanito, and Gaetano Draisci \\ Department of Anesthesiology and Intensive Care, Sacro Cuore Catholic University, Rome, Italy
}

The number of women with major congenital heart defects reaching reproductive age is likely increasing. We herein describe the anesthetic management of a 33-year-old woman at 37 gestational weeks with a history of Glenn surgery who was undergoing an urgent cesarean section due to pathological cardiotocography. Combined spinal-epidural anesthesia was the most suitable technique for urgent cesarean section in our patient with a single ventricle and phasic flow in the pulmonary artery because it provided rapid-onset anesthesia with negligible hemodynamic effects.

Key Words: Glenn circulation, Major congenital heart defect, Obstetric anesthesia.

The number of women with major congenital heart defects reaching reproductive age is likely increasing due to progress in surgical techniques. In this report, we describe the anesthetic management of a pregnant woman with a single ventricle and a history of Glenn surgery who was undergoing an urgent cesarean section (CS). Glenn circulation involves a connection between the superior vena cava and the pulmonary artery that results in passive blood flow to the lungs; thus, the single ventricle must supply cardiac output to both the systemic and pulmonary

Corresponding author: Stefano Catarci, M.D.

Department of Anesthesiology and Intensive Care, Sacro Cuore Catholic University, Largo A. Gemelli 8, 00168 Rome, Italy

Tel: 39-0630154507, Fax: 39-063013450

Email: s.catarci@gmail.com

ORCID: http://orcid.org/0000-0002-3466-6527

Received: September 9, 2015.

Revised: November 27, 2015 (1st); December 12, 2015 (2nd).

Accepted: December 29, 2015.

Korean J Anesthesiol 2016 December 69(6): 632-634

https://doi.org/10.4097/kjae.2016.69.6.632 circulations. The Glenn connection decreases the workload on the single ventricle by diverting blood flow from the upper half of the body directly to the lungs. The inferior vena cava remains connected to the right atrium, creating a right-to-left shunt to allow mixing of oxygenated and deoxygenated blood. Hemodynamic changes related to pregnancy may have detrimental effects on the functional abilities of these patients. Pregnancy and delivery in a woman with a single ventricle is commonly affected by maternal (heart failure exacerbations, arrhythmias, thrombotic events, or bacterial endocarditis) and fetal (spontaneous abortion, premature labor, or neonatal death) complications [1-4]. Labor and delivery by women with a single ventricle can be a serious concern for obstetricians, anesthesiologists, and cardiologists.

\section{Case Report}

A 33-year-old pregnant woman at 37 gestational weeks with a history of major heart surgery was admitted to our institution and scheduled an elective CS. She had been diagnosed with a complex congenital heart defect characterized by dextrocardia, a

(c) This is an open-access article distributed under the terms of the Creative Commons Attribution Non-Commercial License (http://creativecommons.org/ licenses/by-nc/4.0/), which permits unrestricted non-commercial use, distribution, and reproduction in any medium, provided the original work is properly cited. 
criss-cross valvular defect (under-over type) with transposition of the great vessel, a hypoplastic right ventricle, an atrial septal defect, and a ventricular septal defect. At 27 years of age, she had undergone Glenn surgery to allow blood to be routed directly from the superior vena cava to the lungs through phasic flow in the pulmonary artery (bidirectional Glenn shunt). Later, it was recommended that she undergo additional surgery to allow deoxygenated blood returning from the lower part of the body to be diverted directly to the pulmonary circulation (Fontan approach); however, she refused any further procedure.

On admission to the obstetric ward, she was $160 \mathrm{~cm}$ tall and weighed $85 \mathrm{~kg}$ (body mass index $=33.2 \mathrm{~kg} / \mathrm{m}^{2}$ ). A physical examination revealed a good general condition, eupnoea in both the standing and lying positions, a continuous $4 / 6$ heart murmur on both sides of the sternum, no pathological sounds on chest auscultation, digital clubbing, and nail bed cyanosis. Her vital signs were as follows: blood pressure, 135/80 $\mathrm{mmHg}$; heart rate, 65 beats/min; respiratory rate, 15 breaths/min; and oxygen saturation $\left(\mathrm{SaO}_{2}\right), 80 \%$ to $85 \%$ with a $5 \%$ increase after administration of $100 \%$ oxygen via face mask at $4 \mathrm{~L} / \mathrm{min}$. Oral acetylsalicylic acid (100 mg), subcutaneous enoxaparin (4,000 IU; last dose 16 hours before CS), and antenatal vitamins had been administered since early pregnancy. A preoperative electrocardiogram (ECG) and transthoracic echocardiogram showed sinus rhythm without signs of ischemia, an ejection fraction of $60 \%$, dysplasia and severe stenosis of the pulmonary valve, mild left atrio-ventricular valve regurgitation, and mild aortic regurgitation. Her hemoglobin (Hb) level was $12.0 \mathrm{~g} / \mathrm{dl}$ (hematocrit = $36 \%$ ). The patient was classified as New York Heart Association Functional Class II.

The day after admission, she underwent an urgent CS due to pathological cardiotocography (type 2 urgency according to Lucas' classification [5]). The cardiosurgery team was alerted to perform extracorporeal membrane oxygenation if necessary. Upon completion of monitoring (invasive blood pressure, ECG, and $\mathrm{SpO}_{2}$ ) in the operating room, 1,000 $\mathrm{ml}$ of crystalloid was administered over $10 \mathrm{~min}$, and combined spinal-epidural anesthesia using the needle-through-needle technique was performed with the patient in a sitting position. Hyperbaric bupivacaine $(0.5 \%) 5 \mathrm{mg}$ and sufentanil $10 \mu \mathrm{g}$ were injected intrathecally at the L3-L4 interspace. An epidural catheter was positioned in the epidural space, and a $3-\mathrm{ml}$ test dose of $2 \%$ lidocaine with $5 \mu \mathrm{g} / \mathrm{ml}$ epinephrine $(1: 200,000)$ was used to exclude an intravascular or subarachnoid injection. The patient was then placed in the supine position with left uterine displacement, and supplemental oxygen was provided via face mask $\left(\mathrm{FIO}_{2}=1\right)$.

The sensory block rapidly reached the T10 level without significant effects on hemodynamics. Epidural 2\% lidocaine with $1: 200,000$ epinephrine was administered at a rate of $5 \mathrm{ml}$ every $5 \mathrm{~min}$ and titrated up to the T4 level (15 $\mathrm{ml}$ in $15 \mathrm{~min})$. The CS was performed uneventfully. A healthy male newborn was delivered with Apgar scores of 9 and 9 at 1 and $5 \mathrm{~min}$, respectively. Hemodynamic parameters remained stable throughout surgery. The extraction maneuver, blood loss (estimated $300 \mathrm{ml}$ ), and oxytocin infusion did not reduce the blood pressure to $>15 \%$ of baseline. The patient was monitored postoperatively in the coronary care unit for the next 24 hours. Postoperative analgesia involving $10 \mathrm{ml}$ of $0.2 \%$ ropivacaine and $2.5 \mathrm{mg}$ of morphine via the epidural catheter, and $1 \mathrm{~g}$ of acetaminophen four times daily was delivered. The postoperative period was uneventful with no need for transfusion $(\mathrm{Hb}>11 \mathrm{~g} / \mathrm{dl}$ ) or vasoactive drugs. Adequate volume was maintained with a crystalloid infusion of 1,500 $\mathrm{ml}$ per 24 hours and free early oral feeding. An ECG and echocardiogram performed on postoperative days 1 and 2 showed no difference from the preoperative results.

\section{Discussion}

Cases of CS in patients with complex congenital heart disease surgically corrected in childhood are being reported in the literature with increasing frequency [6-8], but none were performed as an urgent procedure requiring rapid-onset anesthesia with poor hemodynamic effects. The superior vena cava of a patient with Glenn circulation connects to the pulmonary artery with passive blood flow to the lungs, and the single ventricle must supply cardiac output for systemic and pulmonary circulation. The cardiovascular changes that occur during pregnancy (increased blood volume, decreased systemic vascular resistance and pulmonary vascular resistance, and increased stroke volume and heart rate) may have substantial consequences in pregnant women with a single ventricle. Therefore, aortocaval compression may have clinically relevant effects and should be avoided in these patients because of the passive blood flow to the lungs [9-14]. As soon as our patient arrived in the operating room, all available options for safe anesthesia were rapidly considered. General anesthesia was eliminated as a possibility, mainly because of the detrimental effects of mechanical ventilation on hemodynamics due to increased intrathoracic pressure; this was particularly true in our patient, in whom the Glenn circulation was strongly volume-responsive, requiring an adequate preload and normal afterload to maintain cardiac output and to avoid the negative inotropic effects of general anesthetics. Therefore, neuraxial anesthesia was considered safer for this patient because acetylsalicylic acid had been discontinued by the obstetrician 3 days before the surgery, when the cardiotocography tracing began to show an abnormal phase patterns and a maternal ECG ruled out any potential thromboembolism risk. The benefits of regional anesthesia for this patient were mainly based on maintaining effective spontaneous ventilation because the negative intrathoracic pressure created during inspiration increases 
blood flow to the lungs, thus improving oxygenation, whereas the positive pressure ventilation caused by general anesthesia may result in decreased preload and cardiac output $[6,7,10]$. In addition, regional anesthesia produces excellent analgesia. Nevertheless, a single injection of spinal anesthesia is usually complicated by quick vasodilation and impaired venous return because of the sympathetic nervous system blockade. Therefore, combined spinal-epidural anesthesia allows adequate analgesia to be reached gradually without severe changes to systemic vascular resistance (and potential reversal of the shunt, leading to maternal hypoxemia). Adequate crystalloid volume replacement and left uterine displacement were crucial for maintaining preload and a stable cardiac output, even though the stability of the hemodynamic parameters allowed us to limit crystalloid administration to a total of $2,000 \mathrm{ml}$ intraoperatively. The oxytocin infusion was limited to the minimum effective dose to maintain stable uterine tone and minimize intraoperative and postoperative blood loss. An oxytocin infusion may be associated with vasodilatation and hypotension and may thus have severe consequences in these patients [15]. Actually, an adequate Hb level was crucial for this patient to guarantee optimal oxygen-carrying capacity, despite the intracardiac shunt. Intraoperative and postoperative blood loss was minimal, so no packed red blood cell transfusions were required; however, a transfusion can be considered in such patients because anemia is poorly tolerated under conditions of chronic cyanosis [6].

In conclusion, combined spinal-epidural anesthesia was the most suitable technique for the urgent CS in our patient with a single ventricle and phasic flow in the pulmonary artery because it provided rapid-onset anesthesia with negligible hemodynamic effects.

\section{References}

1. van der Bom T, Zomer AC, Zwinderman AH, Meijboom FJ, Bouma BJ, Mulder BJ. The changing epidemiology of congenital heart disease. Nat Rev Cardiol 2011; 8: 50-60.

2. Balint OH, Siu SC, Mason J, Grewal J, Wald R, Oechslin EN, et al. Cardiac outcomes after pregnancy in women with congenital heart disease. Heart 2010; 96: 1656-61.

3. Drenthen W, Boersma E, Balci A, Moons P, Roos-Hesselink JW, Mulder BJ, et al. Predictors of pregnancy complications in women with congenital heart disease. Eur Heart J 2010; 31: 2124-32.

4. Khairy P, Ouyang DW, Fernandes SM, Lee-Parritz A, Economy KE, Landzberg MJ. Pregnancy outcomes in women with congenital heart disease. Circulation 2006; 113: 517-24.

5. Lucas DN, Yentis SM, Kinsella SM, Holdcroft A, May AE, Wee M, et al. Urgency of caesarean section: a new classification. J R Soc Med 2000; 93: 346-50.

6. Jooste EH, Haft WA, Ames WA, Sherman FS, Vallejo MC. Anesthetic care of parturients with single ventricle physiology. J Clin Anesth 2013; 25: 417-23.

7. McKinnie JE, Abdullah AN, Ramanathan J. Anesthetic considerations in a parturient with oral-facial-digital syndrome and repaired tetralogy of Fallot with left ventricular dysfunction. Int J Obstet Anesth 2014; 23: 182-5.

8. Wendling AL, Seller A, Peterson E. Case report of a parturient with cyanotic congenital heart disease palliated with a Glenn procedure. J Clin Anesth 2012; 24: 586-9.

9. Chugh R. Management of pregnancy in women with repaired CHD or after the fontan procedure. Curr Treat Options Cardiovasc Med 2013; 15: 646-62.

10. Naguib MA, Dob DP, Gatzoulis MA. A functional understanding of moderate to complex congenital heart disease and the impact of pregnancy. Part II: tetralogy of Fallot, Eisenmenger's syndrome and the Fontan operation. Int J Obstet Anesth 2010; 19: 306-12.

11. Ouyang DW, Khairy P, Fernandes SM, Landzberg MJ, Economy KE. Obstetric outcomes in pregnant women with congenital heart disease. Int J Cardiol 2010; 144: 195-9.

12. Baumgartner H, Bonhoeffer P, De Groot NM, de Haan F, Deanfield JE, Galie N, et al. ESC Guidelines for the management of grown-up congenital heart disease (new version 2010). Eur Heart J 2010; 31: 2915-57.

13. Uebing A, Steer PJ, Yentis SM, Gatzoulis MA. Pregnancy and congenital heart disease. BMJ 2006; 332: 401-6.

14. Dob DP, Yentis SM. Practical management of the parturient with congenital heart disease. Int J Obstet Anesth 2006; 15: 137-44.

15. Stephens LC, Bruessel T. Systematic review of oxytocin dosing at caesarean section. Anaesth Intensive Care 2012; 40: 247-52. 